\title{
ABOUT SYSTEMS OF TELECONTROL - BIOTECHNOLOGY CONTROL
}

\author{
Margarita V. Postnova \\ Volgograd State University, Volgograd, Russian Federation \\ Aleksey V. Sklyar \\ Big Dutchman Ltd., Moscow, Russian Federation
}

\begin{abstract}
Currently, powerful modern poultry farms require built-in logistics with an optimized structure of control and management. Such a system requires formalization and ranking, responding to the tasks of specific divisions of enterprises and poultry farms in general. The analysis of the robots on the Russko-Vysotskaya site shows positive results when the Big Dutchman company introduced the BigFarmNet Manager and AMAKS systems for 11 years of operation of this complex allowing to regulate and control the production processes of egg processing, feeding, drinking, to manage the microclimate of poultry houses in real time from the central office or from a portable personal computer using the Internet.
\end{abstract}

Key words: poultry farms, equipment, control, data collection systems, monitoring.

УДК 654.9

ББК 32.966

\section{О СИСТЕМАХ ТЕЛЕКОНТРОЛЯ - УПРАВЛЕНИЯ БИОТЕХНОЛОГИЯМИ}

\section{Маргарита Викторовна Постнова}

Волгоградский государственный университет, г. Волгоград, Российская Федерация

Алексей Владимирович Скляр

ООО «Биг Дачмен», г. Москва, Российская Федерация

\begin{abstract}
Аннотация. В настоящее время мощные современные птицеводческие хозяйства требуют выстроенной логистики с оптимизированной структурой контроля и управления. Такая система требует формализации и ранжированности, отвечая задачам конкретных подразделений предприятий и птицеводческих хозяйств в целом. Анализ работы на п/ф «Русско-Высоцкая» показал положительные результаты при внедрении компанией «Биг Дачмен» системы «БигФармНет Менеджер» и «АМАКС», в течение 11 лет функционирования данного комплекса позволяющих регулировать и контролировать производственные процессы яйцесбора, кормления, поения, управлять микроклиматом птичников в режиме реального времени из центрального офиса или с переносного персонального компьютера при помощи Интернета.

В Российской Федерации и странах СНГ по ряду объективных причин основным производителем птицеводческой продукции является не фермерство, а крупные птицеводческие хозяйства и объединения. В настоящее время многие из них для снижения себестои- мости птицеводческой продукции стали работать с землей и производить зерновое сырье, что существенно упрочило их положение в условиях рынка и вступления нашей страны во Всемирную торговую организацию. Кроме того, надо отметить, что с модернизацией тех- 
нологического оборудования в птицеводческих хозяйствах резко усилена концентрация птицеводческого поголовья в помещениях: на яичных птицефабриках вместо 25-45 тыс. курнесушек в типовых птичниках размещают по 65-100 тыс. голов, а в нестандартных - до 139 и более, в бройлерных хозяйствах в клеточные батареи одного нетипового птичника высаживают до 200 тыс. бройлеров. В связи с этим наращиваются мощности инкубаториев (на $35,53,65$ и более млн яиц в год), яйцескладов (яйцесортировки до 180 тыс. яиц/ч), цехов убоя-переработки птицы (9-12 тыс. гол./ч) и соответствующего шлейфа вспомогательных подразделений (утилизация стоков, помета, инженерные сети и прочее). Мощное современное предприятие требует выстроенной логистики с оптимизированной структурой контроля и управления. Такая система должна быть формализована и ранжирована, отвечая задачам конкретных подразделений и птицеводческих хозяйств (объединений) в целом.

Сравнительный анализ, например, комплектов технического мониторинга различных производителей (Ивэлси, Ротэм, Севекс, МЭЛ и др.) свидетельствует об отсутствии целостной технико-технологической политики по этому вопросу [2 - 5]. Эти фирмы поставляют предприятиям оборудование для контроля и управления различными технологическими процессами птицеводческого хозяйства, отдавая на откуп предприятию решение вопросов, в каких случаях нужен только контроль, а где управление и объемы параметров, используемых для контроля за конкретным производством (или для управления объектом).

В первую очередь рассматриваемый вопрос необходимо разделить на:

a) системы контроля всех объектов в хозяйстве, нештатные отклонения контролируемых параметров, в которых приводят к быстрому и масштабному ущербу для птицеводческого предприятия или к угрозе безопасности персонала (падеж в течение часа всего поголовья в июле из-за поломки вентиляции, переохлаждение суточных цыплят в зимнюю ночь при аварии отопления, выход из строя аспирации в кормоцехе, прорыв газопровода в помещении и т. п.);

б) системы сбора информации, нужной для выработки оптимального алгоритма уп- равления технологией и оперативной его реализации на практике.

Внедрение первых таких систем в производство позволило, например, определить для птичников минимально-допустимый объем контролируемых параметров, исключающих существенные ущербы для предприятия: наличие напряжения на вентиляторах (контроль аэрации), нормативный уровень температуры воздуха в птичнике, освещение птицезала, контроль закрытого входа в здание. Воду-корм эти системы не контролировали, поскольку их наличие в поилках и кормушках в конце рабочего дня обеспечивало потребности птицы до прихода персонала утром. По инкубаториям первые образцы системы централизованного контроля инкубации (СЦКИ) регулярно контролировали температуру воздуха во всех инкубационных, выводных камерах, инкубатории и поворот лотков с записью (документированием) информации. Это обеспечивало возможность своевременной корректировки оператором инкубатория режима управления инкубированием (при необходимости), которое децентрализовано выполнялось микропроцессором каждого шкафа, а также ввести личную ответственность операторов за качество выполнения режимов инкубирования персоналом смен. Например, последний вариант СЦКИ-комплект «Skiff», разработанный МЭЛ (ООО «МикроЭЛектроника»), позволяющий не только контролировать режимы в инкубатории с дублированием их в диспетчерской птицеводческого хозяйства (для вызова специалистов в любое время суток) и записью данных по партиям, но и централизованно управлять инкубированием, а его модификация - универсальный микропроцессор - дает возможность контролировать и управлять основными технологиями птицеводческого предприятия с учетом базовых ресурсных потоков хозяйства (по приборному контролю выхода яиц и мяса птицы, расхода корма, газа, электроэнергии, воды, горюче-смазочных материалов и пр.). Немаловажно то, что эта система выполняется на беспроводной основе - по официально закрепленному в РФ для производства радиоканалу на частоте 2,4 Ггц, достаточному для устойчивой связи на территориях, занимаемых крупными птицеводческими хозяйствами. О том, насколько важно внедрение в практику птицеводства таких систем 
технического мониторинга, свидетельствуют результаты проведенной нами производственной проверки : на п/ф «Русско-Высоцкая» у 43 бройлерников под бункерами приема корма были установлены тензовесы компании «Биг Дачмен» для непрерывной фиксации на компьютере технологической службы количества комбикорма в конкретных емкостях. Это позволило помимо суточных приростов живой массы и объема выпиваемой воды регистрировать поедаемость корма и соотношение «вода/корм» во все возрастные периоды по объективному приборному контролю - лишь знание комплекса указанных показателей позволяет технологу выводить поголовье на максимальные приросты живой массы, сохранность и лучшие показатели по конверсии корма. В практике работы зоотехнических служб они с внедрением такого мониторинга получили возможность реально управлять технологией, имея возможность своевременно устранять нештатные ситуации при появлениях тенденции выхода контролируемых параметров из нормативного диапазона, что помогло существенно улучшить привесы и конверсию корма. Система контроля корма в названном хозяйстве надежно проработала уже более 11 лет, подобные тензовесы и счетчики расхода воды сейчас используются, в том числе и на других птицефабриках [1]. Кроме того, компанией «Биг Дачмен» разработаны и применяются на птицефабриках системы «БигФармНет Менеджер» и «АМАКС», которые позволяют регулировать и контролировать производственные процессы яйцесбора, кормления, поения, управлять микроклиматом птичников в режиме реального времени из центрального офиса или с переносного персонального компьютера при помощи Интернета.

\section{СПИСОК ЛИТЕРАТУРЫ}

1. Бабочкина, Ю. В. Анализ производительности и оплаты труда на примере ООО «Русско-Высоцкая птицефабрика» Ломоносовского района Ленинградской области / Ю. В. Бабочкина, О.В.Стулова // VI Чаяновские чтения: Экономика и менеджмент АПК: Современные подходы, технологии, опыт: сб. мат. Всерос. науч.-практ. конф. -2016. - С. 101107.

2. Использование оборудования «РОТЕМ» в птицеводстве / В. С. Лукашенко [и др.] // Технологии. Продукты. Оборудование. - 2010. - № 5. - С. 66-67.

3. Лысенко, К. А. Современное состояние и развитие системы микроклимата в животноводческих и птицеводческих помещениях / К. А. Лысенко, А. А. Гончарова // Фундаментальные основы современных аграрных технологий. Техники. Сб. трудов Всеросиссийской научно-практической конференции. Национальный исследовательский Томский политехнический университет. - 2015. - С. 419-421.

4. Маринченко, Т. Е. Состояние и тенденции в птицехозяйстве ЕС / Т. Е. Маринченко // Инновационное обеспечение яичного и мясного птицеводства России. Мат. XVIII Международной конференции. $-2015 .-$ С. 546-551.

5. Щербатюк, М. В. Энергосбережение при обеспечении микроклимата птицеводческих помещений / М. Б. Щербатюк // Проблемы и перспективы инновационного развития агротехнологий: Мат. ХІХ межд. науч.-производств. конф. ФГБОУ ВО Белгородский ГАУ, - Белгород, 2015. -С. 84-85.

\section{Information about the Authors}

Margarita V. Postnova, Doctor of Sciences (Biology), Senior Researcher, Head of Department of Bioengineering and Bioinformatics, Volgograd State University, Prosp. Universitetsky, 100, 400062 Volgograd, Russian Federation, postnova@volsu.ru, biobio@volsu.ru.

Aleksey V. Sklyar, Big Dutchman Ltd., Moscow, Russian Federation.

\section{Информация об авторах}

Маргарита Викторовна Постнова, доктор биологических наук, старший научный сотрудник, заведующая кафедрой биоинженерии и биоинформатики, Волгоградский государственный университет, просп. Университетский, 100, 400062 г. Волгоград, Российская Федерация, postnova@volsu.ru, biobio@volsu.ru.

Скляр Алексей Владимирович, ООО «Биг Дачмен», г. Москва, Российская Федерация. 